\title{
PARTIAL RUPTURE OF THE ANTERIOR CRUCIATE LIGAMENT OF THE KNEE
}

\author{
M. A. FARQUHARSON-ROBERTS, A. H. OSBORNE
}

From the Royal Naval Hospital, Haslar, Gosport

\begin{abstract}
Ten patients are reported who had sustained a partial rupture of the anterior cruciate ligament in a twisting injury of the knee. Nine of the 10 patients presented with a small effusion and pseudo-locking of the knee which was thought to be due to muscular spasm to prevent further ligamentous injury. The patients were examined clinically, under anaesthesia and by arthroscopy and the signs were found to be remarkably similar to those in patients with a tear of the medial meniscus. The mechanism of injury leading to partial rupture of the anterior cruciate ligament is discussed.
\end{abstract}

The anterior cruciate ligament of the knee is commonly injured. Complete rupture of the ligament has long been recognised (Cubbins, Callahan and Scuderi 1937) and usually produces significant bleeding into the joint (Noyes et al. 1980).

Although partial rupture of the anterior cruciate ligament has been reported before (Liljedahl, Lindvall and Wetterfors 1965) it has only been easily diagnosed since arthroscopy made inspection of the knee possible without open operation (Jackson and Dandy 1976). Partial rupture has usually been associated with a gross haemarthrosis (Noyes et al. 1980) and was noted by Jackson and Dandy to present with some clinical features of a torn medial meniscus and O'Connor (1977) reported one case in which it presented with pseudo-locking and haemarthrosis.

We present the history, clinical findings and arthroscopic appearance in 10 patients in whom a partial tear of the anterior cruciate ligament was the main arthroscopic finding after injury.

\section{MATERIAL}

The Royal Naval Hospital, Haslar accepts both Service and civilian patients: the predominance of young sportsmen in the population at risk provides a high proportion of injuries to the knee. Our Service patients are sometimes received from overseas some days or weeks after injury and three of these patients are included in the series. In general, patients with significant undiagnosed injuries of the knee are admitted for examination under anaesthesia and arthroscopy. Clinical examination includes the anterior and posterior drawer tests at 15 and 90 degrees (Torg, Conrad and Kalen 1976) and tests for collateral laxity and rotational instability.

Surgeon Lieutenant-Commander M. A. Farquharson-Roberts, FRCS, Royal Navy, Senior Specialist in Orthopaedics

Surgeon Commander A. H. Osborne, MChOrth, FRCS,

FRCS Ed(Orth), Royal Navy, Consultant Orthopaedic Surgeon

Orthopaedic Department, Royal Naval Hospital, Haslar, Gosport, Hampshire PO12 2AA, England.

Requests for reprints should be sent to Surgeon Lieutenant-Commander M. A. Farquharson-Roberts, RN.

(C) 1983 British Editorial Society of Bone and Joint Surgery $0301-620 \mathrm{X} / 83 / 1019-0032 \$ 2.00$
In a seven-month period in 1981,158 arthroscopies of the knee for acute or chronic injuries were carried out using a Thackray System 80 arthroscope. A 30-degree telescope was used for routine examinations although 0 and 70-degree telescopes were available. A tourniquet was not routinely used. Careful inspection of the anterior cruciate ligament was made and the drawer tests at 15 and 90 degrees repeated under direct vision. Where necessary an arthroscopic probe or hook was used to test the integrity of the ligament.

Partial rupture of the anterior cruciate ligament (Figs 1 and 2) was seen in 10 patients and these form the basis for this paper; patients in whom the rupture was almost complete or in whom only a synovial remnant remained intact were excluded from this series.

\section{RESULTS}

The clinical picture and arthroscopic findings in the 10 patients were remarkably consistent. All patients had sustained a twisting injury, usually in moderate flexion, although one patient had been injured in full flexion; in two patients there had been an additional valgus element to the injury. Only one patient had a clinical haemarthrosis although five patients had a small, bloody effusion, three a small, clear effusion, and one knee was dry. Four of the five patients with medial tenderness were seen to have a subsynovial haematoma on the medial side of the knee with slight laxity to valgus or to anteromedial rotatory strain. One patient had a small tear of the medial meniscus but did not require operation; all the other patients had normal menisci.

The similarity of the clinical picture to that of a torn medial meniscus was striking. Nine of our 10 patients presented with a small effusion and pseudo-locking of the knee, 10 to 25 degrees short of full extension. Five of these patients had marked tenderness on, or just above, the medial line of the joint and in these patients pseudolocking disappeared under general anaesthesia. We postulate that the cause for this surprisingly convincing pseudo-locking is muscular spasm to protect the damaged ligament from further injury.

The patients were treated by application of a plaster cylinder in a slightly flexed position for four weeks, 


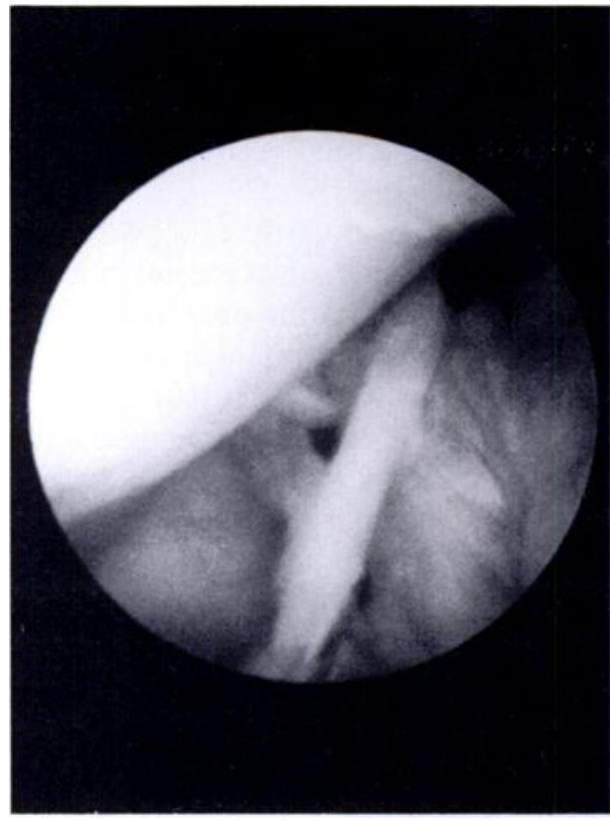

Fig. 1

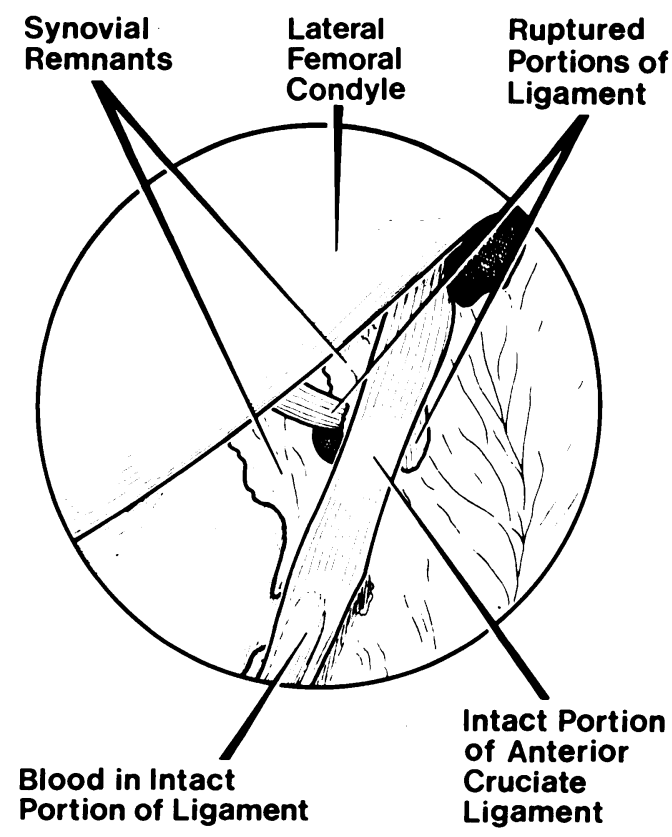

Fig. 2

Figure 1-Arthroscopic photograph of partial rupture of the anterior cruciate ligament taken from the anterolateral approach. Figure 2-Diagrammatic representation of Figure 1.

during which quadriceps exercises were carried out. There has been no evidence of significant instability of the knee at follow-up and therefore we have not had the opportunity to carry out further clinical or arthroscopic examinations on any of the patients.

\section{DISCUSSION}

The mechanisms of injury of the anterior cruciate ligament have been discussed for many years. Wang, Rubin and Marshall (1975) stated that hyperextension will give rise to isolated anterior cruciate rupture although they excluded the possibility of other injuries only by medial arthrotomy and not by arthroscopic examination. Other authors have stated that hyperextension will lead to rupture of the anterior cruciate combined with other ligamentous injuries; they consider that forced internal rotation of the tibia on the femur will give rise to an isolated rupture of the ligament (Kennedy, Weinberg and Wilson 1974; Trickey 1981).

Partial rupture of the anterior cruciate has been reported many times, the incidence varying from 28 per cent in 85 consecutive cases of haemarthrosis of the knee (Noyes et al. 1980) to 34 per cent in a series of anterior cruciate ruptures (Liljedahl et al. 1965). The similarity of the clinical presentation of partial rupture of the anterior cruciate ligament to medial meniscal injury has been mentioned previously but not discussed in detail (Jackson and Dandy 1976; O'Connor 1977).

The anterior cruciate ligament consists of two main groups of fibres (Fig. 3) (Furman, Marshall and Girgis 1976), the anteromedial portion and the posterolateral portion. The anteromedial portion is under maximal tension from 0 to 30 degrees of flexion and some authors consider it to come under tension again at 90 degrees (Abbot et al. 1944; Girgis, Marshall and Al Monajem 1975). The posterolateral portion is considered to be relatively unstressed in flexion while the whole ligament is under least tension from 40 to 50 degrees of flexion (Kennedy et al. 1974). It would therefore seem probable that a positive Lachman test (Torg, Conrad and Kalen 1976) will result if the anteromedial portion of the ligament is ruptured while the usual drawer test performed at 90 degrees of flexion will be negative or only slightly positive; this has been borne out by experiments on cadavers (Furman et al. 1976). Interestingly, our one

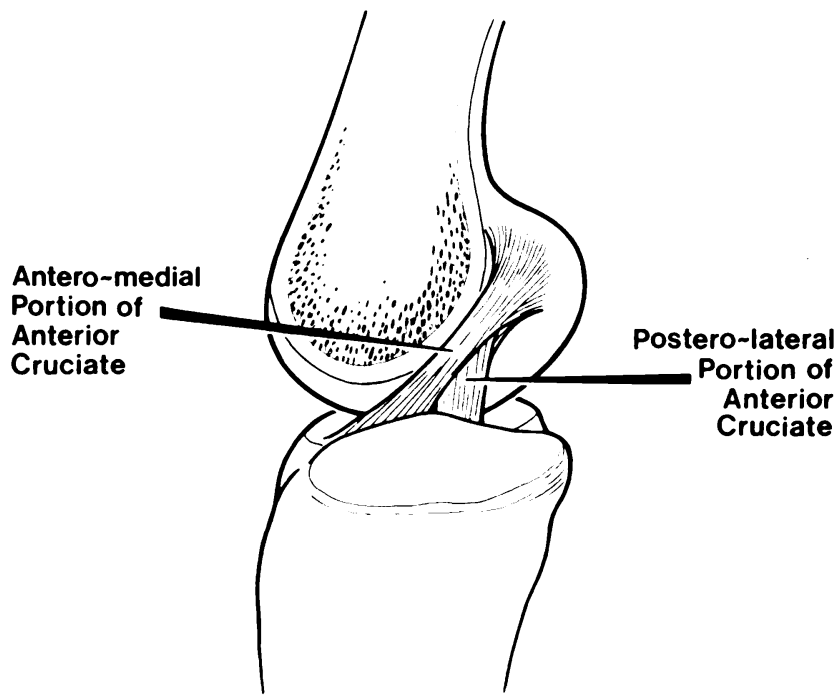

Fig. 3

Diagrammatic representation of the two components of the anterior cruciate ligament. The diagram illustrates the right knee with the medial femoral condyle removed. 
case of a partial tear involving the posterolateral portion had a negative Lachman test but a positive "classical" drawer test, suggesting that the anteromedial portion does not resist this force.

It would appear that a positive Lachman test with a negative or only slightly positive drawer test at 90 degrees of flexion is indicative of partial rupture of the anterior cruciate ligament.

Five of our cases had tenderness of the medial line of the joint and visible subsynovial bleeding at arthroscopy implying concomitant medial capsular injury. This indicates that even in the case of a partial cruciate rupture the rotatory component of the injury gives rise to other damage and makes it unlikely that complete rupture could occur without associated damage to capsular and other ligaments, supporting the contention that it is difficult to conceive an injury that can produce complete discontinuity of the anterior cruciate ligament without causing some damage to one or more of the other ligaments.
The small incidence of haemarthrosis compared with that experienced by others (Kennedy et al. 1974; Noyes et al. 1980) is because the anteromedial portion of the ligament has a relatively poor blood supply (Alm et al. 1974).

The clinical similarity of a partial tear of the anterior cruciate ligament to a medial meniscal tear is completed by the fact that the presenting sign in both cases is a "locked" knee. We hypothesise that muscular spasm, mediated by a neuromuscular reflex initiated by mechanoreceptors in the ligament (Freeman and Wyke 1967), protects against further injury by holding the intact portion of the ligament in a position of minimal tension between 30 and 50 degrees of flexion.

In conclusion, we feel that the condition deserves wider recognition because not only are there indications that a partial rupture may heal if properly managed (Liljedahl et al. 1965), but because further study of such cases may give information concerning the mechanism of complete rupture.

Our thanks are due to Surgeon Captain P. C. Fulford, CVO, OBE, MChOrth, FRCS, RN, for allowing us to report cases under his care and for advice in the preparation of this paper and to Mrs B. Barnes for secretarial assistance.

\section{REFERENCES}

Abbot LC, Sanders JB de CM, Bost FC, Anderson CE. Injuries to the ligaments of the knee joint. J Bone Joint Surg 1944;26:503-21.

Alm A, Ekström H, Gillquist J, Strömberg B. The anterior cruciate ligament : a clinical and experimental study on tensile strength, morphology and replacement by the patellar ligament. Acta Chir Scand 1974; Suppl 445.

Cubbins WR, Callahan JJ, Scuderi CS. Cruciate ligament injuries caused by complete and incomplete dislocations: early and late pathology, symptoms, and a method of repair. Surg Gynecol Obstet 1937; 64: 218-25.

Freeman MAR, Wyke B. The innervation of the knee joint : an anatomical and histological study in the cat. J Anat 1967;101;505-32.

Furman W, Marshall JL, Girgis FG. The anterior cruciate ligament. J Bone Joint Surg [Am] 1976;58-A;179-85.

Girgis FG, Marshall JL, Al Monajem ARS. The cruciate ligaments of the knee joint. Clin Orthop 1975;106;216-31.

Jackson RW, Dandy DJ. Arthroscopy of the knee. (Modern Orthopedic Monographs). New York: Grune and Stratton Inc., 1976:61.

Kennedy JC, Weinberg HW, Wilson AS. The anatomy and function of the anterior cruciate ligament. J Bone Joint Surg [ Am] 1974;56-A :223-35.

Liljedahl SO, Lindvall N, Wetterfors J. Early diagnosis and treatment of acute ruptures of the anterior cruciate ligament. J Bone Joint Surg [Am] $1965 ; 47-A: 1503-13$.

Noyes FR, Bassett RW, Grood ES, Butler DL. Arthroscopy in acute traumatic hemarthrosis of the knee: incidence of anterior cruciate tears and other injuries. J Bone Joint Surg [Am] 1980;62-A:687-95.

O'Connor RL. Arthroscopy. Philadelphia: J. B. Lippincott Company 1977:90.

Torg JS, Conrad W, Kalen W. Clinical diagnosis of anterior cruciate ligament instability in the athlete. Am J Sports Med 1976;4 (2):84-93.

Trickey EL. The anterior cruciate ligament. J Bone Joint Surg [Br] 1981;63-B:466.

Wang JB, Rubin RM, Marshall JL. A mechanism of isolated anterior cruciate ligament rupture. J Bone Joint Surg [Am] 1975;57-A :411-3. 